\title{
MEJORANDO LA LEX IMPERFECTA: TUTELA JUDICIAL EFECTIVA Y CUESTIÓN PREJUDICIAL EN LA PESC (A PROPÓSITO DEL ASUNTO ROSNEFT)
}

\author{
PAZ ANDRÉS SÁENZ DE SANTA MARÍA ${ }^{1}$ \\ pandres@uniovi.es
}

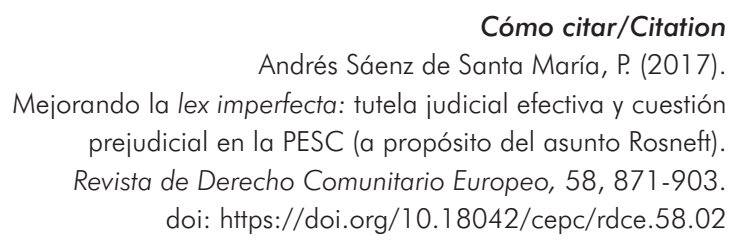

\section{Resumen}

La sentencia del TJ en el asunto Rosneft, en la que proclama su competencia para responder a cuestiones prejudiciales de validez, supone un salto cualitativo en la tarea de aclarar el alcance del control jurisdiccional en la PESC y pone fin a la incertidumbre hasta ahora existente sobre la posibilidad de recurrir a este mecanismo de colaboración judicial en un ámbito en el que la regla general es la ausencia de competencia del TJUE. Partiendo de que la cuestión prejudicial es una modalidad de control de la legalidad, la sentencia destaca su especial relevancia para garantizar la tutela judicial efectiva en un sector que suele requerir la adopción de medidas estatales de aplicación; al mismo tiempo, el Tribunal afirma la aplicación de la jurisprudencia Foto-Frost a las decisiones adoptadas en materia de PESC respecto de las que los tratados le confieren competencia.

Con esta decisión, el TJ contribuye a mejorar la lex imperfecta que rige la PESC, abriendo la puerta a que los órganos jurisdiccionales utilicen la cuestión prejudicial respecto a los actos de ese ámbito que conforme a los tratados no están cubiertos por la inmunidad jurisdiccional.

\footnotetext{
1 Catedrática de Derecho Internacional Público de la Universidad de Oviedo.
} 


\title{
Palabras clave
}

PESC; competencia del TJUE; cuestión prejudicial; medidas restrictivas contra personas físicas o jurídicas; tutela judicial efectiva; artículo 47 de la Carta de los Derechos Fundamentales de la UE; jurisprudencia Foto-Frost.

\section{IMPROVING THE LEX IMPERFECTA: EFFECTIVE JUDICIAL PROTECTION AND PRELIMINARY RULING IN THE CFSP (WITH REGARD TO THE ROSNEFT CASE)}

\begin{abstract}
The judgment of the CJ in the Rosneft case, in which proclaims its competence to answer to preliminary rulings of validity, supposes a qualitative jump in the task of clarifying the scope of judicial review in the CFSP and puts an end to the uncertainty so far existing on the possibility of recourse to this mechanism of judicial cooperation in an area in which the general rule is the lack of competence of the CJEU. On the basis that the preliminary ruling is a means for reviewing the legality, the judgment emphasizes its special relevance to ensure effective judicial protection in a sector that usually requires the adoption of State implementing measures; at the same time, the Court affirms the application of the Foto-Frost case law to the decisions adopted in the field of CFSP with respect to which the treaties give it competence.

With this decision, the CJ contributes to improve the lex imperfecta governing the CFSP, opening the door to the jurisdictional organs use the preliminary ruling with respect to the acts of that area which according to the treaties are not covered by the jurisdictional immunity.
\end{abstract}

\section{Keywords}

CFSP; Jurisdiction of the CJEU; preliminary ruling; restrictive measures against natural or legal persons; effective judicial protection; article 47 of the Charter of Fundamental Rights of the European Union; Foto-Frost case law.

\section{AMÉLIORANT LA LEX IMPERFECTA: PROTECTION JURIDICTIONNELLE EFFECTIVE ET RENVOI PRÉJUDICIEL DANS LA PESC (À PROPOS DE L'AFFAIRE ROSNEFT)}

\section{Résumé}

L'arrêt de la Cour de justice dans l'affaire Rosneft, qui proclame sa compétence pour répondre aux questions préjudicielles de validité, représente un saut qualitatif dans la tâche de clarifier la portée du contrôle judiciaire dans la PESC et met fin à 
l'incertitude jusqu'à présent existant sur la possibilité de recourir à ce mécanisme de coopération judiciaire dans un domaine dans lequel la règle générale est l'absence de compétence de la Cour. Étant donné que le renvoi préjudiciel constitue une modalité du contrôle de la légalité, l'arrêt met en évidence sa pertinence particulière afin d'assurer une protection juridictionnelle effective dans un secteur qui exige généralement l'adoption des mesures étatiques d'application; en même temps, la Cour affirme l'application de la jurisprudence Foto-Frost aux décisions adoptées en matière de PESC dont les traités lui attribuent de compétence.

Avec cette décision, la CJ contribue à améliorer la lex imperfecta qui régit la PESC, en ouvrant la porte à l'utilisation par les organes juridictionnels de la question préjudicielle en ce qui concerne aux actes de ce domaine qui conformément aux traités ne sont pas couverts par l'immunité juridictionnelle.

\section{Mots clés}

PESC; compétence de la Cour de justice; renvoi préjudiciel; mesures restrictives à l'encontre de personnes physiques ou morales; protection juridictionnelle effective; article 47 de la Charte des droits fondamentaux de l'Union Européenne; jurisprudence Foto-Frost. 


\section{SUMARIO}

I. INTRODUCCIÓN: CRÓNICA DE UN PRONUNCIAMIENTO ESPERADO. II. LAS PRIMERAS APROXIMACIONES DEL TJ A SU COMPETENCIA EN LA PESC Y SUS MODESTOS RESULTADOS. III. ¿CUESTIÓN PREJUDICIAL EN LA PESC? UNA APROXIMACIÓN AL ESTADO DE LA CUESTIÓN ANTES DEL ASUNTO ROSNEFT. IV. LA CUESTIÓN PREJUDICIAL LLEGA A LA PESC CON EL ASUNTO ROSNEFT: EL FIN DE LA INCERTIDUMBRE: 1. Aclarando lo pacífico: cuestión prejudicial y art. 40 TUE. 2. Zanjando lo controvertido: cuestión prejudicial y decisiones PESC sobre medidas restrictivas frente a personas físicas o jurídicas: 2. 1. Control de legalidad y art. 275, párrafo segundo, TFUE: in claris... fit interpretatio. 2.2. La especial importancia de la cuestión prejudicial en la PESC para garantizar la tutela judicial efectiva. 2.3. El recurso a los principios de la UE y el papel del art. 47 de la Carta. 2.4. La vigencia de la doctrina Foto-Frost en la PESC: atajando desviaciones peligrosas. 3. El resultado: la proclamación de la competencia prejudicial de validez del TJ sobre los actos PESC sin inmunidad jurisdiccional. 4. ¿̇Y la competencia prejudicial de interpretación? V. REFLEXIÓN FINAL: EL TRIUNFO DE LA COHERENCIA DEL SISTEMA SOBRE LA LITERALIDAD DE LOS PRECEPTOS.

\section{INTRODUCCIÓN: CRÓNICA DE UN PRONUNCIAMIENTO ESPERADO}

La exclusión genérica de la competencia del Tribunal de Justicia de la Unión Europea (TJUE) respecto del ámbito de la Política Exterior y de Seguridad Común (PESC), tan solo atenuada por las previsiones del art. 24, apdo. 1, párrafo segundo, del Tratado de la Unión Europea (TUE) y del art. 275, párrafo segundo, del Tratado de Funcionamiento de la Unión Europea (TFUE), no ha impedido la formulación de tranquilizadoras predicciones sobre algunos aspectos abiertos de esta regulación y por tanto sobre la posibilidad de interpretaciones constructivas por parte del tribunal ${ }^{2}$, el cual a su vez

2 Así, Loreta ŠALTINYTĖ indicó que «The change in perspective of the manner of regulating the ECJ jurisdiction could be sufficient for the Court to interpret the am- 
ha contribuido a alimentar las expectativas. Así, en su por lo demás controvertido y criticado Dictamen sobre la adhesión de la Unión Europea (UE) al Convenio Europeo de Derechos Humanos (CEDH), apuntó que «el Tribunal de Justicia aún no ha tenido ocasión de precisar el alcance de las limitaciones de su competencia resultantes, en materia de PESC, de dichas disposiciones ${ }^{3}$. Poco después, el abogado general Jääkinen, en sus conclusiones en el asunto Elitaliana/Eulex Kosovo, advertía de que «los órganos jurisdiccionales de la Unión Europea no podrán eludir en el futuro controversias relativas a la insuficiente protección de los derechos de los particulares en el marco de la acción exterior» ${ }^{4}$.

La sentencia dictada por el TJ en el asunto Rosneft, proclamando su competencia para responder a cuestiones prejudiciales de validez, supone un salto cualitativo en la tarea jurisprudencial de aclarar el alcance del control jurisdiccional en este sector. El objeto principal de este trabajo es analizar su contenido y alcance desde esta concreta perspectiva; para ello, nos ocuparemos primero de valorar los pronunciamientos anteriores del Tribunal de Justicia (TJ) en relación con su competencia en la PESC y asimismo tendremos presente el previo estado de la cuestión sobre la posibilidad de formular cuestiones prejudiciales en este ámbito, para luego centrarnos en los diferentes aspectos del razonamiento judicial en el caso concreto y finalizar con una reflexión general sobre el significado del pronunciamiento ${ }^{6}$.

biguities in favour of establishing jurisdiction", "Jurisdiction of European Court of Justice over Issues relating to the Common Foreign and Security Policy under the Lisbon Treaty», Jurisprudencija/Jurisprudence, 1 (119), 2010, pp. 275-276, disponible en https://www.mruni.eu/upload/iblock/dca/16saltinyte.pdf (consultado por última vez el 25.9.2017). Por su parte, según Christophe HILLION «although its jurisdiction is more restricted in the CFSP context than on the TFEU terrain, the Union's judiciary is certainly less powerless as regards the former than it used to be, and arguably less powerless than it might be surmised under the post-Lisbon dispensation" ("A Powerless Court? The European Court of Justice and the Common Foreign and Security Policy», en Marise CREMONA, Anne THIES (eds.), The European Court of Justice and External Relations Law. Constitutional Challenges, Hart Publishing, Oxford-Portland, 2016, pp. 69-70).

3 Dictamen del Tribunal de Justicia 2/13, EU:C:2014:2454, apdo. 251.

4 Conclusiones del abogado general Jääskinen en el asunto Elitaliana/Eulex Kosovo, C-439/13 P, EU:C:2015:2416, punto 66.

5 Sentencia del Tribunal de Justicia de 28 de marzo de 2017, Rosneft, C-72/15, EU:C:2017:236.

6 En coherencia con este enfoque, el estudio no abarcará las cuestiones sustantivas de validez abordadas por el TJ tras responder afirmativamente a la primera cuestión pre- 


\section{LAS PRIMERAS APROXIMACIONES DEL TJ A SU COMPETENCIA EN LA PESC Y SUS MODESTOS RESULTADOS}

Con anterioridad al asunto Rosneft, el TJ ya había tenido alguna ocasión para empezar a abordar esta tarea de precisar su competencia en un ámbito respecto del que los Estados miembros vienen manifestando su voluntad de mantenerlo al margen del control jurisdiccional.

En el asunto del Acuerdo UE-Mauricio, a propósito de la competencia del TJ para apreciar la infracción del art. 218.10 TFUE y ante la pretensión del Consejo ${ }^{7}$ de que la decisión impugnada pertenecía exclusivamente al ámbito de la PESC, el abogado general Bot recordó los arts. 24, apdo. 1, párrafo segundo TUE y 275 TFUE para decir que «De estas disposiciones se desprende que aunque la regla general es la falta de competencia del Tribunal de Justicia en materia de PESC, ésta no escapa totalmente a la vigilancia del juez de la Unión ${ }^{8}$. En su sentencia, el TJ fue más claro, y aunque reconoció que «el Tribunal de Justicia, en principio, no tiene competencia en relación con las disposiciones referidas a la PESC o con los actos adoptados sobre la base de éstas», añadió que dado que los citados artículos introducen una excepción a la regla de la competencia general que el art. 19 TUE confiere al Tribunal de Justicia para garantizar el respeto del derecho en la interpretación y aplicación de los tratados, "deben interpretarse restrictivamente»"

A partir de ahí, la consideración del art. 218.10 TFUE como base jurídica procedimental general le permitió considerarse competente, por entender que no cabe sostener que el alcance de la limitación que representa una excepción a la competencia del TJ implica excluir la competencia de este "para interpretar y aplicar una disposición como la contenida en el artículo 218 TFUE, que no guarda relación con la PESC, incluso aunque ella misma

judicial. Tampoco se ocupará del control judicial de las medidas restrictivas frente a personas físicas o jurídicas a través del recurso de anulación, dimensión en el que la competencia expresamente reconocida por los tratados al TJUE ya ha dado lugar a una nutrida jurisprudencia y generado una notable producción doctrinal.

7 Apoyado por la República Checa, Francia, Suecia y Reino Unido.

8 Conclusiones del abogado general Bot en el asunto Parlamento/Consejo, C-658/11, EU:C:2014:41, punto 136.

9 Sentencia del Tribunal de Justicia Parlamento/Consejo, C-658/11, EU:C:2014:2025, apdos. 69 y 70. La posición favorable a la interpretación restrictiva de la exclusión de la competencia del TJUE es reiterada en las Sentencias del Tribunal de Justicia Elitaliana/Eulex Kosovo, C-439/13 P, EU:C:2015:753, apdo. 42, y H/Consejo y Comisión, C-455/14 P, EU:C:2016:569, apdo. 40. 
prevea el procedimiento con arreglo al cual se ha adoptado un acto referente a la $\mathrm{PESC} »^{10}$.

En el posterior asunto del Acuerdo UE-Tanzania, la República Checa, como coadyuvante del Consejo, solicitó al Tribunal que reconsiderara o matizara su jurisprudencia sobre el art. 218.10 TFUE establecida en la sentencia anterior, de forma que el TJ debería limitarse a declarar el incumplimiento de la obligación de informar al Parlamento, pero sin poder anular la decisión impugnada, lo que llevó a la abogada general Kokott a observar que «El Tribunal de Justicia o tiene la competencia o no la tiene. Las excepciones a su competencia requieren una disposición expresa y se han de interpretar restrictivamente. Ni en el artículo 24 TUE, apdo. 1, párrafo segundo, sexta frase, ni en el artículo 275 TFUE, párrafo primero, se establecen graduaciones respecto a las facultades de los tribunales de la Unión para conocer de recursos de anulación en relación con el artículo 40 TUE o con el artículo 218 TFUE, apartado $10 »^{11}$. En su sentencia de 14 de junio de 2016, el TJ no entró a valorar esta cuestión, consideró infringida esta disposición y anuló la decisión del Consejo relativa a la celebración del acuerdo ${ }^{12}$.

El hecho de que en ambos asuntos se cuestionara como primer motivo la elección de la base jurídica conectaba estos casos con la primera de las excepciones contempladas en el art. 275, párrafo segundo, TFUE, esto es, el art. 40 TUE, pero esta circunstancia no dio lugar a consideraciones relevantes. En efecto, en el asunto del Acuerdo UE-Mauricio, el abogado general señaló que «es indispensable definir los límites existentes entre la PESC y las otras políticas de la Unión». Esta obligación resulta de la aplicación recíproca de la cláusula de no afectación entre las competencias de la Unión en materia de PESC y las derivadas de otras políticas de la Unión, prevista en el artículo $40 \mathrm{TUE}_{\aleph^{13}}$, pero el Tribunal no sintió la necesidad de invocar expresamente esta disposición. A su vez, en el caso del Acuerdo UE-Tanzania, la abogada general lamentó que el PE no se hubiera referido en ningún momento expresamente al art. 40 TUE, porque consideraba que era «evidente que en el fondo su argumentación se dirige a la cuestión allí regulada de la delimitación entre la PESC, por un lado, y los ámbitos políticos «comunitarizados», por

10 Apdo. 73 de la sentencia (ibid.).

11 Conclusiones de la abogada general Kokott en el asunto Parlamento/Consejo, C-263/14, EU:C:2015:729, punto 47.

12 Sentencia del Tribunal de Justicia Parlamento/Consejo, C-263/14, EU:C:2016:435.

13 Conclusiones del abogado general Bot en el asunto Parlamento/Consejo, op. cit., nota 8 , punto 86 . 
otro»" En esta ocasión, el TJ sí advirtió de que «Por lo que respecta a los actos adoptados sobre la base de una disposición relativa a la PESC, incumbe al Tribunal de Justicia velar, en particular, con arreglo al artículo 275 TFUE, párrafo segundo, primer segmento de frase, y al artículo $40 \mathrm{TUE}$, por que la ejecución de dicha política no afecte a la aplicación de los procedimientos y al alcance respectivo de las atribuciones de las instituciones establecidos en los Tratados para el ejercicio de las competencias de la Unión con arreglo al Tratado FUE» ${ }^{15}$, pasando después a la valoración de la base jurídica material.

En el asunto ElitalianalEulex Kosovo, frente a la posición del Tribunal General (TG), que no entró a dilucidar la competencia de los órganos jurisdiccionales de la Unión para conocer del asunto en base a las disposiciones relativas a la PESC, el TJ decidió plantearla de oficio, y dado que se trataba de la adjudicación de un contrato público de servicios por el jefe de la Misión EULEX Kosovo que generó gastos a cargo del presupuesto de la UE, consideró — sin traer a colación expresamente el art. 40 TUE_ que, habida cuenta de las circunstancias propias del caso de autos, no puede considerarse que el alcance de la excepción a la competencia del Tribunal de Justicia establecida en el art. 24 TUE, apdo. 1, párrafo segundo, última frase, y en el artículo 275 TFUE llegue hasta el extremo de excluir la competencia del Tribunal de Justicia para interpretar y aplicar las disposiciones del Reglamento financiero en materia de adjudicación de contratos públicos ${ }^{16}$.

En el asunto H/Consejo y Comisión, mientras que el TG declaró inadmisible, por no considerarse competente, el recurso contra unas decisiones de cambio de destino de una magistrada italiana adoptadas por el jefe de personal de la Misión de Policía de la UE (MPUE) en Bosnia y Herzegovina, el TJ afirmó su competencia. En su argumentación, el Tribunal recurrió a consideraciones vinculadas a los principios en los que se basa la UE y también

14 Conclusiones de la abogada general Kokott en el asunto Parlamento/Consejo, punto 43 (op. cit., nota 11).

15 Apdo. 42 de la sentencia (op. cit., nota 12).

16 Apdo. 49 de la sentencia (op. cit., nota 9). El abogado general, en las conclusiones presentadas el 21 de mayo de 2015 tras la decisión del Tribunal de reabrir la fase oral, entre otros argumentos invocó el art. 40 TUE, puntualizando que «La novedad que aporta esta disposición respecto al antiguo artículo 47 TUE (según estaba redactado antes del Tratado de Lisboa) reside en que la «obligación de no asignación» opera en los dos sentidos, en la medida en que tiene por objeto tanto "proteger» las políticas de la Unión de un posible solapamiento con los mecanismos de la cooperación intergubernamental como «proteger» la PESC contra posibles efectos similares de las políticas de la Unión» (conclusiones del abogado general Jääskinen en el asunto Elitalianal Eulex Kosovo, op. cit., nota 4, punto 27). 
a otras más específicas relacionadas con el trato otorgado a los agentes de la Unión. Así, el TJ, de un lado, señaló que la existencia misma de un control jurisdiccional efectivo para garantizar el cumplimiento de las disposiciones del derecho de la Unión es inherente a la existencia del Estado de derecho ${ }^{17}$; de otro, tras reconocer que las decisiones controvertidas se inscriben en el contexto de la PESC, anunció que «tal circunstancia no puede llevar necesariamente a excluir la competencia del juez de la Unión» ${ }^{18}$, pasando a analizar el caso desde la perspectiva del estatuto de los agentes de la Unión, y en este ámbito, la similitud de funciones desarrolladas tanto por los agentes de la UE destinados en comisión de servicios a la MPUE como por los procedentes de los Estados miembros, así como el hecho de que en todo caso las decisiones de asignación de recursos humanos son actos de gestión de personal ${ }^{19}$, le conduce a considerarse competente ${ }^{20}$.

La doctrina no ha dejado de señalar las singularidades del razonamiento del Tribunal ${ }^{21}$. En este sentido, hay que destacar que el argumento consistente

17 Apdo. 41 de la sentencia (op. cit., nota 9).

18 Apdo. 43 de la sentencia (ibid.).

19 Véase el apdo. 55 de la sentencia (ibid.). El Tribunal encuentra corroborada su posición por el hecho de que tanto la Decisión (PESC) 2015/1835 del Consejo, de 12 de octubre de 2015, por la que se determinan el estatuto, la sede y la forma de funcionamiento de la Agencia Europea de Defensa, como la Decisión 2012/C 12/04 de la Alta Representante de la Unión para Asuntos Exteriores y Política de Seguridad, de 23 de marzo de 2011, por la que se fija el régimen aplicable a los expertos nacionales destinados en comisión de servicio en el Servicio Europeo de Acción Exterior, atribuyen competencia al TJUE para resolver los recursos interpuestos por los expertos nacionales en comisión de servicios (véase el apdo. 56 de la sentencia). Como ha señalado Graham BUTLER, «The Council has basically shot itself in the foot as a result of the EDA Decision last year. Perhaps without realising the full ramifications of Council Decision 2015/1835/CFSP in 2015, it is now having a spill-over effect. The Council itself trampled over its own arguments by granting the Court jurisdiction within one CFSP Decision on the EDA in 2015, but then trying to claim that it does not have the same adjudication powers within another early CFSP Decision on the EUPM. This argument wasn't sustainable [...]» («H $v$. Council: Another Court breakthrough in the Common Foreign and Security Policy»", EU Law Analysis, disponible en http:// eulawanalysis.blogspot.com.es/2016/07/h-v-council-another-court-breakthrough. html, consultado por última vez el 25.9.2017).

20 Apdo. 59 de la sentencia (op. cit., nota 9).

$21 \mathrm{Al}$ respecto, se ha dicho con razón que «To interpret all matters relating to CFSP missions, including the administrative, procedural, and operational issues as being «CFSP acts» to escape judicial oversight of the EU judicial body would have been over-interpretation of the restrictions on the Court which have been set down by 
en invocar el principio de igualdad y el Estado de derecho solo es utilizado por el TJ como introducción a las valoraciones vinculadas al régimen del personal, que son sobre las que realmente apoya su decisión en el caso. Como se ha indicado, "In a Union that is based on the values of equality and the rule of law, the right to (equality of treatment as regards) effective judicial review thus also applies with respect to CFSP. Of course, there is a certain tension between this observation and the jurisdictional carve-out laid down in Articles 24 (1) TEU and 275 TFEU. The legal argumentation developed on the basis of the ECJ's jurisdiction in relation to staff management allowed the Court to circumvent this fundamental issue» ${ }^{22}$.

Además, el Tribunal no entró a considerar en ningún momento unas propuestas de interpretación planteadas por la recurrente y por la Comisión que habrían conducido a una ampliación de la competencia del TJUE en el ámbito de la PESC. En efecto, la recurrente defendió que una decisión relativa al cambio de destino de un miembro del personal es una decisión meramente administrativa y no un acto en el ámbito de la PESC a los efectos de los arts. 24 TUE, apdo. 1, y 275 TFUE; asimismo, alegó que el concepto de «medidas restrictivas» que figura en el art. 275 TFUE comprende todos los actos de la

the Treaties» (BUTLER, op. cit., nota 19), pero también se ha advertido de que «Nevertheless, the CJEU asserted jurisdiction by insisting that all staff should be treated equally when it comes to access to justice. For those seeking judicial review over CFSP acts, H. v. Council et al. is a new tool in the toolbox. Still, apart from other staff cases, it is difficult to envisage where the equality argument advanced by the CJEU in $H . v$. Council et al. could be applied in the future.» (Stian Øby JOHANSEN, «H. v. Council et Al. - A Minor Expansion of the CJEU's Jurisdiction Over the CFSP», European Papers-European Forum, Highlight of 7 October 2016, vol. 1, núm. 3, 2016, p. 1299, disponible en http://www.europeanpapers.eu/en/europeanforum/h-v-council-minorexpansion-cjeu-over-cfsp, consultado por última vez el 25.9.2017). En una línea similar, también se ha comentado que «By characterising the issue in $\mathrm{H}$ v. Council et al. as one of staff management with certain operational aspects from which the staff management dimension could not be disentangled, the ECJ was able to avoid, in an entirely legitimate manner, articulating a more comprehensive understanding of the limits of the CJEU's jurisdiction in CFSP matters» (Thomas VERELLEN, «H v. Council: Strengthening the Rule of Law in the Sphere of the CFSP, One Step at a Time», European Papers-European Forum, Insight of 9 December 2016, vol. 1, núm. 3, 2016, pp. 1048-1049, disponible en http://www.europeanpapers.eu/en/europeanforum/h-v-council-strengthening-the-rule-of-law-in-the-sphere-of-the-cfsp, consultado por última vez el 25.9.2017). Peter VAN ELSUWEGE, "Upholding the rule of law in the Common Foreign and Security Policy: H v. Council,, Common Market Law Review, vol. 54, 2017, p. 850. 
Unión que afectan negativamente a los intereses de las personas, incluidas las decisiones impugnadas ${ }^{23}$.

A su vez, la Comisión expuso que los artículos 24 TUE, apdo. 1, y 275 TFUE debían interpretarse en el sentido de que excluyen la competencia del TJUE únicamente respecto de los actos comprendidos en el ámbito de la PESC que constituyen una expresión de la política exterior soberana («actes de gouvernement»), y no de los actos que se limitan a aplicar dicha política. Con carácter subsidiario, la Comisión sostuvo también que los arts. 24 TUE, apdo. 1, y 275 TFUE solo excluyen el control por el TJUE de los supuestos incumplimientos de las disposiciones de la PESC, pero no el control de los supuestos incumplimientos de otras disposiciones del derecho de la Unión. Así pues, el TJUE sería competente para controlar la legalidad de actos adoptados en el ámbito de la PESC cuando la supuesta invalidez de los mismos derivase de una posible vulneración de disposiciones ajenas al ámbito de la PESC. Con el fin de conseguir que los términos de «determinadas decisiones contempladas en el párrafo segundo del artículo 275 [TFUE]», empleados en el art. 24 TUE, apdo. 1, párrafo segundo, última frase, fueran interpretados en el sentido de que designan todo acto adoptado por una institución de la Unión contra una persona que produce frente a ella efectos jurídicos que pueden menoscabar sus derechos fundamentales, la Comisión planteaba dos interpretaciones alternativas del art. 24 TUE, apdo. 1, párrafo segundo, última frase, y del art. 275 TFUE, párrafo primero, que conducían a resultados diferentes en términos de competencia del juez de la Unión, la primera consistente en examinar el contenido del acto, de la acción o de la omisión en cuestión y la segunda basada en los motivos invocados ante el juez de la Unión ${ }^{24}$.

Como ya se ha apuntado, el TJ guardó silencio sobre estas propuestas. En definitiva, la valoración general sobre los primeros pronunciamientos del Tribunal relativos a su competencia en la PESC consiste inevitablemente en que los resultados son modestos y confinados a aspectos muy específicos, alejados del núcleo competencial duro del sistema jurisdiccional de la UE. Seguramente ello explica la expectación levantada por el asunto Rosneft, en el que la claridad de la

23 Véase el punto 31 de las conclusiones del abogado general Wahl en el asunto H/Consejo y Comisión, C-455/14 P, EU:C:2016:212, y los apdos. 29-30 de la sentencia (op. cit., nota 9).

24 Véase el punto 33 de las conclusiones del abogado general, el cual no compartió estos puntos de vista (op. cit., nota 23; la fundamentación de su rechazo se encuentra en los puntos 52-66 y 73-81); véanse también los apdos. 32-34 de la sentencia (op. cit., nota 9). Con ocasión del Dictamen 2/13, la Comisión ya defendió interpretaciones tendentes a extender la competencia del TJUE (véase la opinión de la abogado general Kokott, EU:C.2014:2475, puntos 86-87). 
primera cuestión prejudicial planteada por el Tribunal Superior de Justicia (Inglaterra y País de Gales) permitía esperar un pronunciamiento directo por parte del TJ sobre la aplicación o no en la PESC de un mecanismo fundamental en el sistema jurisdiccional de la UE como es la cuestión prejudicial ${ }^{25}$.

La petición de decisión prejudicial versaba sobre la validez de determinadas disposiciones de la Decisión 2014/512/PESC del Consejo, de 31 de julio de $2014^{26}$, y sobre la validez e interpretación del Reglamento (UE) n. ${ }^{\circ}$ 833/2014 del Consejo, de 31 de julio de $2014^{27}$. Esta petición se presentó en el marco de un litigio entre la empresa rusa especializada en los sectores petrolífero y gasístico Rosneft y las autoridades británicas en relación con las medidas adoptadas por estas en aplicación de las normas citadas ${ }^{28}$. En concreto, la primera pregunta era:

25 Diversas contribuciones doctrinales previas a la sentencia en el asunto Rosneft han apuntado la importancia del caso; a título de ejemplo, cabe citar: BUTLER, op. cit, nota 19; VERELLEN, op. cit., nota 21, p. 1045; VAN ELSUWEGE, op. cit., nota 22, pp. 842 y 857; Paul James CARDWELL, «The Legalisation of European Union Foreign Policy and the Use of Sanctions", Cambridge Yearbook of European Legal Studies, vol. 17, 2015, p. 303; Ramses A. WESSEL, «Lex Imperfecta: Law and Integration in European Foreign and Security Policy», European Papers, vol. 2, 2016, pp. 460-462, disponible en http://www.europeanpapers.eu/en/e-journal/lex-imperfecta-law-and-integration-european-foreign-and-security-policy (consultado por última vez el 25.9.2017).

26 Relativa a medidas restrictivas motivadas por acciones de Rusia que desestabilizan la situación en Ucrania (DO L 229, de 31 de julio de 2014, p. 13; esta decisión ha sido modificada en varias ocasiones).

27 Relativo a medidas restrictivas motivadas por acciones de Rusia que desestabilizan la situación en Ucrania (DO L 229, de 31 de julio de 2014, p. 1, y corrección de errores en DO L 246, de 21 de agosto de 2014, p. 59; el Reglamento también ha sido modificado en varias ocasiones).

28 Rosneft cuestionaba la validez de las disposiciones mencionadas por entender que la Decisión 2014/512 fue adoptada en infracción del art. 40 TUE; que las referidas disposiciones eran incompatibles con el Acuerdo de colaboración UE-Rusia; que el Consejo, al adoptarlas, incumplió su obligación de motivación, vulneró el derecho de defensa, el derecho a la tutela judicial efectiva y el derecho a acceder al expediente; que se había vulnerado el principio de igualdad de trato; que las disposiciones controvertidas en el litigio principal eran nulas por haber incurrido el Consejo en desviación de poder y por existir contradicción entre los términos de la Decisión 2014/512 y los del Reglamento n. ${ }^{\circ}$ 833/2014, respectivamente; por último, que el Consejo violó el principio de proporcionalidad y vulneró los derechos fundamentales que le asisten, y en concreto la libertad de empresa y el derecho de propiedad. 
Habida cuenta, en particular, de los artículos 19 TUE, apartado 1, 24 TUE y 40 TUE, del artículo 47 [de la Carta de los Derechos Fundamentales de la Unión Europea (en lo sucesivo, "Carta»)] y del artículo 275 TFUE, párrafo segundo, ¿es competente el Tribunal de Justicia para pronunciarse con carácter prejudicial, con arreglo al artículo 267 TFUE, sobre la validez del artículo 1, apartado 2, letras b) a d), y apartado 3, de los artículos 4, 4 bis y 7 y del anexo III de la Decisión $2014 / 512$ ? $^{29}$

\section{III. ¿̇CUESTIÓN PREJUDICIAL EN LA PESC? UNA APROXIMACIÓN AL ESTADO DE LA CUESTIÓN ANTES DEL ASUNTO ROSNEFT}

Durante los trabajos de la Convención Europea, se barajó la posibilidad de atribuir al TJ competencia prejudicial en el ámbito de la $\mathrm{PESC}^{30}$; sin embargo, las divergencias entre los miembros del Círculo acerca de las competencias del Tribunal en el ámbito de la PESC tuvieron como resultado que no se hiciera ninguna propuesta en este sentido, como tampoco se hizo desde el Praesidium ${ }^{31}$,

29 Apdo. 38 de la sentencia (op. cit., nota 5). Las restantes cuestiones prejudiciales se referían a las cuestiones de validez planteadas por Rosneft resumidas en la nota anterior; asimismo, el órgano jurisdiccional remitente preguntaba por la interpretación de los principios de seguridad jurídica y de nulla poena sine lege certa en relación con la imposición de sanciones penales por parte de los Estados prevista por el Reglamento y también por la interpretación de la expresión "asistencia financiera», recogida en el art. 4, apdo. 3, del Reglamento, y de las expresiones «esquisto» y «aguas con una profundidad superior a 150 metros» contempladas tanto en la Decisión como en el Reglamento, así como por la interpretación del art. 5 del Reglamento respecto a si prohíbe la emisión de certificados internacionales representativos de títulos.

30 Un documento preparado por la Secretaría en el Círculo de Debate sobre el TJ apuntaba entre los posibles enfoques: «The first option of extending the Court's powers would involve giving the national courts the possibility of using the preliminary ruling procedure on interpretation before the Court of Justice when they have to decide on questions relating to the implementation by the Member States of CFSP decisions to which they are required to give effect» (CERCLE I, WD 10, 12 de marzo de 2003, CONV 689/1/03 REV 1, anexo, p. 5).

31 Véanse los documentos CONV 689/1/03 REV 1 y CONV 734/03, pp. 27-28. Sobre las posiciones en el seno del Círculo de Debate y la regulación final en el tratado constitucional, puede verse Jorge PUEYO LOSA, «El Tribunal de Justicia y el futuro constitucional de la Unión Europea», en VV.AA., Constitución y ampliación de la Unión Europea. Crisis y nuevos retos, Tórculo, Santiago de Compostela, 2004, pp. 129182. Como indica Loreta ŠALTINYTÉ, «In the end, the key proposal to provide the ECJ with the jurisdiction over CSFP matters, including the extension of preliminary 
por lo que las previsiones de la Constitución Europea ${ }^{32}$ recibieron finalmente la redacción ahora contenida en los arts. 24 TUE y 275 TFUE.

Por otra parte, no deja de tener interés el hecho de que en dos asuntos y por vías distintas antes de Rosneft ya había aflorado ante el TJ la hipótesis de su competencia para resolver cuestiones prejudiciales en la PESC. La primera ocasión vino de mano de la Comisión con motivo del Dictamen 2/13 sobre la adhesión de la UE al CEDH. En sus observaciones ${ }^{33}$, esta institución se esforzó por ofrecer interpretaciones que permitieran demostrar que era posible un control jurisdiccional más amplio que garantizara una tutela judicial efectiva de los particulares. Entre ellas, se encontraba la de que el art. 275, párrafo segundo, TFUE podía entenderse en el sentido de que faculta al TJUE no solo para pronunciarse sobre recursos de anulación interpuestos por particulares contra medidas restrictivas, sino también para conocer de reclamaciones de daños y perjuicios y abordar peticiones de decisión prejudicial de los tribunales nacionales en materia de PESC ${ }^{34}$. En su opinión en ese procedimiento, la abogado general Kokott mostró dudas sobre la viabilidad jurídica de la propuesta y descartó expresamente esta última posibilidad ${ }^{35}$. La abogado

reference procedure to this area, was found politically unacceptable» (op. cit., nota 2, p. 265).

32 Contenidas en el art. III-376 del Tratado por el que se establece una Constitución para Europa.

33 Apoyadas por una minoría de Estados y fuertemente rechazadas por el Consejo, Francia y el Reino Unido.

34 Véase el punto 86 de la opinión de la abogada general Kokott en el Dictamen 2/13 (op. cit., nota 24).

35 Según la abogada general, «Por una parte, la interpretación de la Comisión pasa por alto la relación entre regla general y excepción que subyace al artículo 275 TFUE; también desnaturaliza el principio de no competencia de los tribunales de la Unión en la PESC que se consagra en el artículo 24 TUE, apartado 1, concretamente en la frase sexta de su párrafo segundo, y en el artículo 275 TFUE, párrafo primero, al convertirlo justo en lo contrario. Por otra parte, al defender que el Tribunal de Justicia es competente para conocer de procedimientos prejudiciales y reclamaciones de daños y perjuicios en el contexto de la PESC, la Comisión choca con el tenor inequívoco de la segunda variante que recoge el párrafo segundo del artículo 275 TFUE, el cual menciona sólo la competencia para pronunciarse sobre los recursos de anulación interpuestos por particulares, con arreglo al artículo 263 TFUE, párrafo cuarto, contra medidas restrictivas, y no otros objetos ni clases de recurso, ni menos aún las remisiones prejudiciales de tribunales nacionales del artículo 267 TFUE» (punto 89 de la opinión, ibid.). 
general invocó además los trabajos preparatorios de la Convención Europea ${ }^{36}$ y también se ocupó de negar la pertinencia de la jurisprudencia traída a colación por la Comisión para sustentar su tesis; en particular, ante la invocación de los asuntos Gestoras pro Amnistía y otros/Consejo y Segi y otros/Consejo, recordó que el TJ denegó explícitamente el reconocimiento, en el tercer pilar de entonces, de recursos distintos de los que estaban previstos expresamente en el Tratado UE en la versión que este había recibido con el Tratado de Ámsterdam $^{37}$. Todo ello le llevó a concluir que «en la PESC los Tratados no otorgan al Tribunal de Justicia la potestad de pronunciarse prejudicialmente, tal como indican el artículo 24 TUE, apartado 1, concretamente en la frase sexta de su

36 Poniendo de relieve que «en su momento sí se llegó a debatir una estructuración más generosa de las competencias de los tribunales de la Unión en la PESC, pero las propuestas presentadas en ese sentido no gozaron del consenso necesario. Al final, la Convención y, siguiendo su criterio, las dos Conferencias Intergubernamentales para, respectivamente, el Tratado Constitucional y el Tratado de Lisboa se ciñeron en la PESC a un modelo fundamentalmente intergubernamental en el que se darían a los tribunales de la Unión competencias reducidas» (punto 90 de la opinión, ibid.).

Punto 94 de la opinión (ibid.). En la misma línea, para José MARTÍN Y PÉREZ DE NANCLARES, «la propuesta interpretativa de la Comisión resultaba realmente imaginativa y atractiva para superar los problemas derivados de la falta de competencia del TJUE en materia de PESC, pero era contra legem por ir claramente en contra de la formulación del art. 275 TFUE; ultra vires por resultar contraria a la voluntad expresa de los Estados plasmada en el Tratado de Lisboa, por haberse descartado tal consideración tanto durante los debates de la Convención Europea a propósito de los entonces art. III-282 del Tratado por el que se establece una Constitución para Europea (CONV 689/1/03, de 16 de abril de 2003, apartados 5 y 7; CONV 734/03, de 2 de mayo de 2003) como durante la Conferencia Intergubernamental previa al Tratado de Lisboa; e incluso imprecisa, por fundarse en una jurisprudencia previa del Tribunal de Justicia sobre el Espacio de Libertad, Seguridad y Justicia (cuando se ubicaba en el tercer pilar de la Unión) que no resultaba difícilmente trasladable al ámbito de la PESC (jurisprudencia Gestoras Pro Amnistía y Segi EU:C:2007:115; EU:C:2007:116)» («El TJUE pierde el rumbo en el Dictamen 2/13: ¿̇merece todavía la pena la adhesión de la UE al CEDH?», RDCE, núm. 52, 2015, p. 846, nota 70). Según Stefan REITEMEYER y Benedikt PIRKER, a la vista del tenor del art. 275, párrafo segundo, TFUE, la interpretación sugerida por la Comisión resulta difícilmente convincente ( Opinion 2/13 of the Court of Justice on Access of the EU to the ECHR - One Step Ahead and Two Steps Back», European Law Blog, disponible en http://europeanlawblog.eu/2015/03/31/opinion-213-of-the-court-of-justice-onaccess-of-the-eu-to-the-echr-one-step-ahead-and-two-steps-back/, consultado por última vez el 25.9.2017). 
párrafo segundo, y el artículo 275 TFUE, párrafo primero ${ }^{38}$. No obstante la enjundia y relevancia de las consideraciones expuestas tanto por la Comisión como por la abogada general, en su dictamen el TJ se limitó a su ya citada lacónica advertencia de que aún no había tenido ocasión de pronunciarse sobre el alcance de los límites a su competencia ${ }^{39}$.

A su vez, en el asunto H/Consejo y Comisión, el abogado general Whal también entendió que la tutela judicial efectiva le correspondía a los órganos jurisdiccionales nacionales y por ello estimó que el TG había concluido acertadamente que correspondía a los tribunales italianos examinar la legalidad de las decisiones impugnadas, pero contrariamente a lo sostenido por la abogado general Kokott defendió que podían plantear cuestiones prejudiciales pues «no cabe descartar que los órganos jurisdiccionales nacionales competentes puedan albergar dudas en cuanto al alcance de su competencia para controlar la legalidad de las decisiones impugnadas y en cuanto a las posibles consecuencias de dicho control» ${ }^{40}$, y destacó las ventajas de este mecanismo en el ámbito de la $\mathrm{PESC}^{41}$. Como ya se ha señalado, tampoco en este caso el TJ consideró procedente ocuparse de este tema.

38 Punto 100 de la opinión (ibid.). La cursiva está en el original.

39 Apdo. 251 del Dictamen del Tribunal de Justicia 2/13, op. cit., nota 3. Con toda razón, José MARTÍN Y PÉREZ DE NANCLARES ha apuntado que el Tribunal se pronuncia «sin el más mínimo esfuerzo argumental» y que «Ni siquiera se toma la molestia de rebatir la batería de argumentos que le habían brindado tanto la abogado general como los intervinientes en el procedimiento - muy en especial la Comisión y algunos Estados miembros_- para salvar las dudas de compatibilidad» (op. cit., nota 37, pp. 844 y $845-846)$.

40 En cuyo caso - apuntó- «recuerdo a esos órganos jurisdiccionales que son libres - y, en ocasiones, tienen la obligación — de presentar una petición de decisión prejudicial ante el Tribunal de Justicia con arreglo al artículo 267 TFUE. En tal caso, el Tribunal de Justicia podrá incluso colaborar con dichos órganos jurisdiccionales para resolver el asunto de que conozcan, sin por ello rebasar los límites de su competencia impuestos por los artículos 24 TUE, apartado 1, y 275 TFUE» (apdo. 90 de las conclusiones, op. cit., nota 23).

41 El abogado general indicó: "Considero que las peticiones de decisión prejudicial deben ser recibidas favorablemente, por cuanto ofrecen dos ventajas inmediatamente apreciables. En primer lugar, permiten al Tribunal de Justicia determinar si, en el contexto de un procedimiento prejudicial, es competente para interpretar el acto que ha sido impugnado ante el órgano jurisdiccional nacional o las disposiciones pertinentes relativas a la PESC invocadas por la parte recurrente. En efecto, es posible que el órgano jurisdiccional nacional no tenga claro si el acto o las disposiciones de la Unión en cuestión en el procedimiento principal se excluyen de la competencia del Tribunal de Justicia con arreglo a la norma general establecida en los artículos 24 
Todavía desde el plano de los asuntos planteados ante el TJUE, hay que añadir que en sus conclusiones en el asunto $A$ y otros $^{42}$, la abogada general Sharpston ha compartido la postura del abogado general Wathelet en sus conclusiones en el asunto Rosne $\mathrm{ft}^{43}$ presentadas poco antes y favorables a considerar que el control de legalidad mencionado en el art. 24. 1 TUE comprende también el mecanismo de remisión prejudicial. Más adelante volveremos sobre este caso.

Al reflexionar sobre si el mecanismo de la cuestión prejudicial tiene cabida en la PESC, la doctrina presenta diferentes posiciones, que oscilan entre quienes defienden sin titubeos una interpretación del art. 275, párrafo segundo, TFUE, no limitada al recurso de anulación, incluyendo por tanto la cuestión prejudicial ${ }^{44}$, y los que consideran que el tenor literal de ese precepto

TUE, apartado 1, y 275 TFUE, o, por el contrario, pueden estar comprendidos en alguna de las excepciones a dicha norma (por ejemplo, en caso de que el artículo 40 TUE sea aplicable). En segundo lugar, y lo que es más importante, permiten que el Tribunal de Justicia interprete disposiciones de la Unión de carácter horizontal (de fondo o de forma) o principios generales del Derecho de la Unión (como el principio de cooperación leal o el deber de diligencia) que también pueden ser aplicables en el procedimiento principal. En particular, el Tribunal de Justicia puede aclarar los límites de la autonomía procesal nacional, exponiendo las consecuencias jurídicas que se desprenden de la obligación del órgano jurisdiccional nacional de establecer, de conformidad con el artículo 19 TUE, apartado 1, las vías de recurso necesarias para garantizar la tutela judicial efectiva de las personas» (apdo. 91 de las conclusiones; ibid.). Al mismo tiempo, el abogado general rechazó expresamente la posibilidad de que un órgano jurisdiccional nacional pueda declarar la nulidad de un acto adoptado por una institución o un organismo de la UE y reitera la jurisprudencia Foto-Frost (véanse los apdos. 101-102).

42 Conclusiones de la abogado general Sharpston en el asunto A y otros, C-158/14, EU:C:2016:734.

43 Conclusiones del abogado general Whatelet en el asunto Rosneft, C-72/15, EU:C:2016:381.

44 Es el caso de Christophe HILLION, quien se apoya en varios elementos: «To begin with, neither Article 24 (1) TEU nor Article 275 (2) TFEU explicity limits the proceedings to «direct actions». Instead, the Court is empowered «to rule on proceedings brought in accordance with the conditions laid down in the fourth paragraph of Article 263». Arguably, Article 275 (2) TFEU does not seem to restrict the Court's intervention only to the proceedings of Article 263 (4) TFEU, but rather establishes the "conditions» under which its control is to be exercised, namely the locus standi requirements, and the grounds of review. Moreover, both Article 275 (2) TFEU and Article 24 (1) TEU entrust the Court with the power of «reviewing the legality» of CFSP sanctions. The case law indicates that such a review of legality is not limited 
no permite esas interpretaciones extensivas ${ }^{45}$, pasando por los que se inclinan por apuntar la posibilidad de que el TJ tenga competencia pero sin afirmarla tajantemente ${ }^{46}$.

to annulment proceedings. Instead, «requests for preliminary rulings which seek to ascertain the validity of a measure constitute, like actions for annulment, means for reviewing the legality of European Union acts»» (op. cit., nota 2, pp. 51-52).

45 Así, Thomas VERELLEN indica que «as Art. 275 TFEU only expressis verbis provides for jurisdiction via the médium of the annulment action, judicial restraint makes it unlikely that the ECJ will take a position on the broader question of whether preliminary rulings procedures are authorised [...]» (op. cit., nota 21, p. 1045; véanse también los autores citados en la nota 37). Por su parte, Maja BRKAN también invoca el tenor literal de la disposición, a lo que añade la mens legislatoris pues, en su opinión, "the goal of the Treaty was that such acts can be attacked only by persons who fulfil the standing requirements from Article 263(4) TFEU, so that a general review of the legality of such acts that can arise under the preliminary rulings on validity should not be permitted» («The Role of the European Court of Justice in the Field of Common Foreign and Security Policy After the Treaty of Lisbon: New Challenges for the Future», en Paul James CARDWELL [ed.], EU External Relations Law and Policy in the Post-Lisbon Era, T.M.C. Asser Press, La Haya, 2012, p. 111).

Refiriéndose al art. 275, párrafo segundo, TFUE y a las competencias del TJUE allí establecidas, Ricardo ALONSO GARCÍA dice compartir las dudas de Alicia HINAREJOS acerca de si la apertura parcial del control del Tribunal a los actos enteramente PESC «se extendería hasta el punto de permitir su cuestionamiento (al margen del artículo 40 TUE) a través de cuestiones prejudiciales de validez»» («Lisboa y el Tribunal de Justicia de la Unión Europea», Working Paper IDEIR, núm. 1, 2010, p. 11, disponible en https://www.ucm.es/data/cont/docs/595-2013-11-07-lisboa\%20y\%20el\%20derecho. pdf, consultado por última vez el 25.9.2017). A su vez, Loreta ŠALTINYTÉ observa que «Although the Lisbon Treaty did not include any specific provision concerning the avalaibility of the preliminary reference procedure over questions relating to the validity or interpretation of CSFP measures, it equally did not provide that such references were not allowed» (op. cit., nota 2, p. 267; también, en p. 267, citando —al igual que Ricardo ALONSO GARCÍA - a Takis TRIDIMAS, «The European Court of Justice and the Draft Constitution: A Supreme Court for the Union?», en Takis TRIDIMAS; Paolisa NEBBIA (eds.), European Union Law for the Twenty-First Century: Rethinking the New Legal Order, Volumen 1, Hart Publishing, Oxford, 2004, p. 128. De forma más desiderativa, José Manuel CORTÉS MARTÍN, tras aludir al papel de los tribunales nacionales en relación con las medidas de ejecución de la PESC, añade que «el TJUE debería poder intervenir en este control vía cuestión prejudicial cuando sea necesario» («Autonomía versus sumisión a un control externo en materia de derechos fundamentales: consideraciones sobre el Dictamen TJUE No 2/13 relativo a la adhesión al CEDH», $R G D E$, núm. 37, 2015, p. 33). 
De esta forma, el recorrido por el estado de la cuestión hasta aquí realizado nos deja un escenario abierto en el que tanto una solución como la contraria encontrarían apoyo argumental, lo que refuerza el interés de la decisión en el caso que motiva esta contribución. El propio abogado general había reconocido que la petición de decisión prejudicial planteada por el Tribunal Superior de Justicia (Inglaterra y País de Gales) «es de la mayor importancia, pues ha de llevar al Tribunal de Justicia a pronunciarse sobre su competencia para controlar la validez e interpretar, con carácter prejudicial, los actos adoptados por la Unión en materia de política exterior y de seguridad común [...] cuando parece que el artículo 24 TUE, apartado 1, párrafo segundo, última frase, y el artículo 275 TFUE excluyen tal posibilidad», de forma que «el presente asunto ofrece al Tribunal de Justicia la posibilidad de identificar los actos que, de acuerdo con el apartado 252 de su dictamen $2 / 13$ [...] «en el estado actual del Derecho de la Unión [...] escapan al control jurisdiccional del Tribunal de Justiciam» ${ }^{47}$.

\section{LA CUESTIÓN PREJUDICIAL LLEGA A LA PESC CON EL ASUNTO ROSNEFT: EL FIN DE LA INCERTIDUMBRE}

Con su decisión en el asunto Rosneft, el TJ pone fin a la incertidumbre y se declara competente para pronunciarse con carácter prejudicial con arreglo al art. 267 TFUE en los ámbitos de la PESC sobre los que los tratados prevén la posibilidad de control jurisdiccional. En su razonamiento, el Tribunal de un lado aglutina y confiere pleno sentido a sus pronunciamientos anteriores, de otro proyecta y al mismo tiempo reafirma nociones fundamentales sobre las características del control jurisdiccional en la UE ya formuladas en su jurisprudencia anterior. En su tarea, pudo contar con unas elaboradas conclusiones, en las que destacan la exposición de la competencia del TJUE en la PESC utilizando los conceptos de cláusulas carve-out y claw-back, que sin duda va a dejar huella en la doctrina ${ }^{48}$.

47 Conclusiones del abogado general Wathelet en el asunto Rosneft, C-72/15, puntos 2 y 3 (op. cit., nota 43).

48 La cláusula carve-out, consagrada en los arts. 24 TUE, apdo. 1, párrafo segundo y 275 TFUE, párrafo primero, establece una excepción a la regla de la competencia general conferida por el art. 19 TUE al TJUE; la cláusula claw-back, contenida en los arts. 24 TUE, apdo. 1, párrafo segundo, última frase y 275 TFUE, párrafo segundo, asegura un control jurisdiccional limitado de determinados actos PESC (véase el apdo. V. A. 2. de las conclusiones, op. cit., nota 43). 
Tras rechazar las propuestas de declarar inadmisible la cuestión prejudicial $^{49}$, el TJ la escinde en dos partes: por una parte, se trata de determinar si es competente para, en virtud de una cuestión prejudicial, controlar si el Consejo respetó el art. 40 TUE cuando adoptó el acto PESC; por otra, dilucidar si es competente para controlar la legalidad de las medidas restrictivas adoptadas frente a personas físicas o jurídicas cuya aprobación se establece en el acto PESC por la vía de un procedimiento prejudicial de los previstos en el art. 267 TFUE a instancias de un tribunal nacional que albergue dudas sobre la validez de dichas medidas ${ }^{50}$.

\section{ACLARANDO LO PACÍFICO: CUESTIÓN PREJUDICIAL Y ART. 40 TUE}

Para responder a este primer interrogante, al TJ le basta con apuntar que los tratados no establecen ninguna modalidad concreta en relación con el control judicial del respeto de la mencionada disposición, de forma que dicho control está incluido en la competencia general que el art. 19 TUE confiere al Tribunal de Justicia para garantizar el respeto del derecho en la interpretación y aplicación de los tratados, lo que incluye la cuestión prejudicial; por consiguiente, afirma que es competente para pronunciarse sobre una petición de decisión prejudicial que se refiera a la compatibilidad de la Decisión $2014 / 512$ con el art. 40 TUE $^{51}$.

\section{ZANJANDO LO CONTROVERTIDO: CUESTIÓN PREJUDICIAL Y DECISIONES PESC SOBRE MEDIDAS RESTRICTIVAS FRENTE A PERSONAS FÍSICAS O JURÍDICAS}

Resuelto con facilidad lo anterior, el Tribunal se centra en el meollo de lo planteado por el tribunal británico: la cuestión prejudicial de validez respecto de decisiones PESC que establezcan medidas restrictivas frente a personas

49 Los gobiernos estonio y polaco dudaban de la necesidad de dar la respuesta, lo que el TJ rechaza recordando el juicio de pertinencia que incumbe al órgano jurisdiccional nacional y la ausencia de evidencias de que la cuestión no guarde relación con la realidad o con el litigio principal o sea hipotética (véanse los apdos. 49-52 de la sentencia, $o p$. cit., nota 5). Por su parte, el Consejo intentó centrar el asunto exclusivamente en el Reglamento (UE) no 833/2014, adoptado sobre la base del art. 215 TFUE, soslayando así la Decisión 2014/512/PESC, pero el TJ tampoco aceptó este enfoque (véanse los apdos. 53-56 de la sentencia, ibid.).

50 Apdo. 61 de la sentencia (ibid.).

51 Apdos. 62-63 de la sentencia (ibid.). 
físicas o jurídicas. En su argumentación, se va a apoyar en varios postulados y principios.

\subsection{Control de legalidad y art. 275 , párrafo segundo, TFUE: in claris... fit interpretatio}

En primer lugar, la sentencia recurre a las dos dimensiones del control de legalidad comunitario puestas de manifiesto en diversas sentencias ${ }^{52}$, y dado que «la remisión prejudicial para que se aprecie la validez de un acto constituye, de la misma manera que el recurso de anulación, una modalidad del control de legalidad de los actos de la Unión" " ${ }^{53}$, la conclusión es que «Esa característica esencial del sistema de tutela judicial de la Unión alcanza al control de legalidad de las decisiones por las que se establecen medidas restrictivas frente a personas físicas o jurídicas en el marco de la PESC» ${ }^{54}$.

La transposición de estos consolidados conceptos al ámbito de las competencias del TJUE en la PESC es plenamente coherente ${ }^{55}$. No obstante, es evidente que el tenor literal del art. 275, párrafo segundo, TFUE planteaba

52 Así, señala que «Es jurisprudencia reiterada que el control de la legalidad de los actos de la Unión garantizado en virtud de los Tratados por el Tribunal de Justicia se fundamenta en dos procedimientos judiciales complementarios. En efecto, el Tratado FUE, mediante sus artículos 263 y 277, por una parte, y mediante su artículo 267, por otra, ha establecido un sistema completo de vías de recurso y de procedimientos destinado a garantizar el control de la legalidad de los actos de la Unión, confiando dicho control al juez de la Unión [...] A este sistema completo de vías de recurso y de procedimientos le es inherente el hecho de que se confiera a los justiciables, en el marco de un recurso interpuesto ante un tribunal nacional, el derecho a cuestionar la legalidad de disposiciones incluidas en actos de la Unión que sirvan de base para la resolución o acto nacionales adoptados respecto de ellos, invocando la ilegalidad de tales disposiciones e instando a dicho órgano jurisdiccional, que no es competente para declarar por sí mismo tal nulidad, a interrogar al Tribunal de Justicia al respecto por la vía de una remisión prejudicial...» (apdos. 66 y 67 de la sentencia, ibid.). Apdo. 68 de la sentencia (ibid.).

54 Apdo. 69 de la sentencia (ibid.).

55 En este sentido, Christophe HILLION había advertido de que «That judicial control of CFSP restrictive measures should not be limited to direct actions under Article 264 (3) TFEU would indeed be consistent with the notion that the treaties establish a «complete system of judicial remedies", a notion coined by the Court of Justice to compensate for its strict reading of the admissibility conditions of Article 263 (4) TFEU. If the other avenues of the "complet system» were foreclosed, the very notion of completeness to which the Court has recurrently referred in the post-Lisbon EU context, would then become relative» (op. cit., nota 2, pp. 52-53). 
un problema para encajar el mecanismo de la cuestión prejudicial, habida cuenta de la referencia específica y exclusiva a «los recursos interpuestos en las condiciones contempladas en el párrafo cuarto del artículo 263 del presente Tratado». Para salvar este obstáculo, el abogado general había recurrido a señalar las diferencias de redacción entre el art. 24, apdo. 1, párrafo segundo, última frase, y el art. 275, párrafo segundo, TFUE, «que consiste en que el artículo 275 TFUE, párrafo segundo, limita el control de la legalidad de las decisiones por las que se establezcan medidas restrictivas frente a personas físicas o jurídicas a los recursos de anulación interpuestos por dichas personas con arreglo al párrafo cuarto del artículo 263 TFUE, mientras que el artículo 24 TUE [...] vuelve a establecer la competencia del Tribunal de Justicia para controlar, en general, la legalidad de «determinadas decisiones contempladas en el párrafo segundo del artículo 275 [TFUE]» [...]»" ${ }^{56}$, proponiendo que «la cláusula «claw-back» del artículo 275 TFUE, párrafo segundo, que reconduce a la norma de base ha de interpretarse en sentido lato, teniendo en cuenta los términos más extensivos del artículo 24 TUE [...] ${ }^{57}$, de manera que el control de legalidad de tales decisiones puede hacerse tanto por medio de un recurso de anulación como con carácter prejudicial ${ }^{58}$.

Por su parte, el Tribunal asume y expresa con mayor claridad la idea que subyace en las conclusiones, entendiendo que de los tratados no se desprende que los recursos de anulación sean la única modalidad de control de legalidad de las decisiones por las que se establezcan medidas restrictivas frente a personas físicas o jurídicas, ni que la remisión prejudicial para que se aprecie la validez de un acto no constituya una modalidad de dicho control de legalidad, de forma que "cuando el artículo 24 TUE, apartado 1, párrafo segundo, última frase, remite al artículo 275 TFUE, párrafo segundo, no lo hace para determinar el tipo de procedimiento en que el Tribunal de Justicia puede controlar la legalidad de determinadas decisiones, sino para fijar el tipo de decisiones cuya legalidad puede ser controlada por el Tribunal de Justicia en cualquier procedimiento cuyo objeto sea ese mismo control de legalidad ${ }^{59}$.

\footnotetext{
56 Punto 61 de las conclusiones (op. cit., nota 43).

57 Punto 64 de las conclusiones (ibid.).

58 Para ello, el abogado general se apoya en los dos aspectos del control de legalidad establecidos jurisprudencialmente y en la interpretación restrictiva propugnada por el propio TJ respecto de la exclusión de su competencia en la PESC (véanse los puntos 62-64 de las conclusiones, ibid.).

59 Apdo. 70 de la sentencia (op. cit., nota 5).
} 
Es claro que estamos ante una interpretación creativa que incluso - como se ha apuntado - podría ser demasiado creativa ${ }^{60}$, pero ha sido a base de interpretaciones creativas como el TJUE ha sentado postulados imprescindibles del ordenamiento de la Unión y su sistema jurisdiccional.

\subsection{La especial importancia de la cuestión prejudicial en la PESC para garantizar la tutela judicial efectiva}

En segundo lugar, el TJ destaca la singular relevancia que puede tener el mecanismo del reenvío prejudicial en la PESC, teniendo en cuenta la existencia de medidas nacionales de aplicación y la obligación de los Estados miembros de velar por la conformidad de sus políticas nacionales con las posiciones de la Unión en este ámbito. Con esto, además de añadir un elemento más a su teorización de la cuestión prejudicial ${ }^{61}$, incorpora otro argumento para justificar la interpretación del art. 275, párrafo segundo TFUE. En él, vincula el papel de la cuestión prejudicial a la tutela judicial efectiva, estimando que «dado que la aplicación de una decisión por la que se establezcan medidas restrictivas frente a personas físicas o jurídicas es en parte responsabilidad de los Estados miembros, la remisión prejudicial para que se aprecie la validez

60 Stian Øby JOHANSEN y Alexander AMESEN apuntan que «The consequence of the interpretation is that the TFEU article 275 is seen as having a different (narrower) scope than TEU article 24(1) i.f. - a surprising result, since most have regarded that the two provisions were intended to be identical» ("Jurisdiction, legislation, and creative interpretations in the Opinion of AG Wathelet in C-72/15 Rosneft», VerfBlog, disponible en http://verfassungsblog.de/jurisdiction-legislation-and-creative-interpretations-in-the-opinion-of-ag-wathelet-in-c-7215-rosneft/, consultado por última vez el 25.9.2017). En un comentario posterior, Stian Øby JOHANSEN apunta una divergencia lingüística entre las versiones francesa e inglesa; la primera favorecería la interpretación propuesta por el abogado general y acogida por el TJ ( $J$ Judicial control of EU foreign policy: the ECJ judgment in Rosneft», EU Law Analysis, disponible en http://eulawanalysis.blogspot.com.es/2017/03/judicial-control-of-eu-foreign-policy. html, consultado por última vez el 25.9.2017). También, para Graham BUTLER "there is no doubt that it had to be slightly inventive given that is clearly a shortcoming in the drafting of the Treaties» («A Question of Jurisdiction: Art. 267 TFEU Preliminary References of a CFSP Nature», European Papers-European Forum, Insight of 1 April 2017, 2017, vol. 2, núm. 1, p. 207, disponible en http://europeanpapers. eu/en/europeanforum/a-question-of-jurisdiction-art-267-tfeu-preliminary-references-of-a-cfsp-nature, consultado por última vez el 25.9.2017).

61 Teorización que sobresale en los Dictámenes del Tribunal de Justicia 1/09, EU:C:2011:123 y 2/13 (op. cit., nota 3). 
de un acto cumple una función esencial a la hora de garantizar la tutela judicial efectiva ${ }^{62}$, por lo que rechaza una interpretación restrictiva de su competencia que sería contraria a los objetivos de este principio y del mecanismo de la cuestión prejudicial ${ }^{63}$.

En esta parte de su razonamiento, el Tribunal invoca por analogía su jurisprudencia anterior sobre la interpretación restrictiva de la exclusión de su competencia en la PESC, a la que nos hemos referido más arriba, y también sus decisiones de 27 de febrero de 2007 en los asuntos Gestoras pro Amnistía y otros/Consejo y Segi y otros/Consejo, en lo que atañe a la interpretación efectuada por el TJ del entonces art. 35, apdo. 1, TUE para admitir la posibilidad de someterle con carácter prejudicial cualquier asunto relativo a disposiciones adoptadas por el Consejo dirigidas a producir efectos jurídicos frente a terceros, con independencia de su naturaleza o forma.

Estas dos sentencias ya habían sido invocadas en alguno de los casos anteriores relacionados con las competencias del TJUE en la PESC, siempre con la finalidad de justificarlas. Así lo hizo la Comisión con motivo del Dictamen 2/13 entre sus argumentos para apoyar las interpretaciones amplias del art. 275, párrafo segundo TFUE que propugnaba. La abogada general dijo entonces que «en los asuntos mencionados el Tribunal de Justicia optó por la interpretación del Derecho originario mediante la que mejor se garantizaba la eficacia práctica de los tipos de procedimiento previstos expresamente en los Tratados» ${ }^{64}$, añadiendo — como ya se ha indicado más arriba- que le parecía «revelador que en las sentencias Gestoras Pro Amnistía y Segi el Tribunal de Justicia denegara explícitamente el reconocimiento, en el «tercer pilar» de aquel entonces, de recursos distintos de los que estaban previstos expresa-

62 Apdo. 71 de la sentencia (op. cit., nota 5). Al plantear la cuestión prejudicial, el tribunal remitente puso mucho énfasis en la necesidad de garantizar la tutela judicial efectiva (véanse los apdos. 34 y 54 de la sentencia, ibid.).

63 Véase el apdo. 75 de la sentencia (ibid.). De esta forma, el Tribunal señala que "puesto que el Tribunal de Justicia dispone, en virtud del artículo 24 TUE, apartado 1, y del artículo 275 TFUE, párrafo segundo, de competencia material para pronunciarse sobre la validez de actos de la Unión, en particular, cuando se trata de medidas restrictivas frente a personas físicas o jurídicas, resultaría contrario a la sistemática de la tutela judicial efectiva instaurada por los Tratados interpretar esa última disposición en el sentido de que excluye la posibilidad de que los tribunales de los Estados miembros planteen al Tribunal de Justicia cuestiones relativas a la validez de decisiones del Consejo por las que se establezca la adopción de dichas medidas» (apdo. 76 de la sentencia, ibid.).

64 Opinión de la abogado general en el Dictamen 2/13, punto 93 (op. cit., nota 24). Cursiva añadida. 
mente en el Tratado UE» ${ }^{65}$. También citó estos casos el abogado general en el asunto H/Consejo y Comisión ${ }^{66}$, así como la Comisión ${ }^{67}$.

La referencia que se hace a estos casos en Rosneft, que se encuentra también en las conclusiones del abogado general ${ }^{68}$, avala los intentos anteriores y amplía el alcance de lo estipulado en las sentencias de 27 de febrero de 2007, pues con independencia de lo acertado de la ampliación, el dato señalado por J. Kokott de que entonces se trataba de procedimientos previstos explícitamente en los tratados respecto de aquel pilar — aunque con limitaciones-, y ahora no, es un hecho incontestable ${ }^{69}$.

\subsection{El recurso a los principios de la UE y el papel del art. 47 de la Carta}

En tercer lugar, el Tribunal enlaza con el caso $H c$. Consejo para integrar en su argumentación el principio del Estado de derecho, al que es inherente la existencia de un control jurisdiccional efectivo. Al respecto, no deja de tener interés el hecho de que en aquel asunto el abogado general había descartado expresamente este razonamiento de carácter constitucional ${ }^{70}$. Tal posición,

65 Punto 94 de la opinión (ibid.).

66 Véanse los puntos 50 y 91 y las notas 35, 39 y 63 de las conclusiones (op. cit., nota 23).

67 Véase el apdo. 31 de la sentencia, en la que el TJ también invoca el asunto Segi y otros c. Consejo pero con la finalidad de traer a colación los principios de igualdad y Estado de derecho (op. cit., nota 9).

68 Véase el punto 55 y las notas 28 y 29 (op. cit., nota 43).

69 De lo que tampoco cabe duda es de que la pregunta que se hacía Ana Isabel SANTAMARÍA DACAL en su comentario a estas sentencias ya ha encontrado respuesta («Las Sentencias Segi y Gestoras del TJCE: ¿un sermón sin mayores consecuencias o un toque de atención", REDE, núm. 22, 2007, pp. 313-322).

70 «En el presente asunto, carece de pertinencia el hecho de si este sistema es compatible con el principio de que la Unión se basa en el Estado de Derecho. En efecto, tal sistema es el resultado de una decisión consciente adoptada por los redactores de los Tratados, que optaron por no atribuir al TJUE una competencia general y absoluta sobre el conjunto de los Tratados de la Unión. En consecuencia, el Tribunal de Justicia no puede interpretar las normas establecidas en los Tratados para ampliar su competencia más allá de lo que establece el tenor de dichas normas o para crear nuevas soluciones no previstas en éstas. Al igual que las restantes instituciones de la Unión, también el Tribunal de Justicia debe respetar el principio de atribución de competencias. En particular, con arreglo al artículo 13 TUE, apartado 2, el Tribunal de Justicia «actuará dentro de los límites de las atribuciones que le confieren los Tratados, con arreglo a los procedimientos, condiciones y fines establecidos en los mismos»» (punto 49 de las conclusiones, op. cit., nota 23). 
ya desautorizada entonces por el TJ al citar expresamente este principio en su sentencia, queda con Rosneft definitivamente arrumbada. Ni que decir tiene que también queda en la misma posición la de la abogada general Kokott en su opinión con motivo del Dictamen 2/13. Su colega Wathelet la trae a colación en sus conclusiones para discrepar de ella precisamente sobre la base de estos principios, señalando que la afirmación de que en la PESC los tratados no otorgan al TJ la potestad de pronunciarse prejudicialmente es «difícilmente conciliable con el artículo 23 TUE», según el cual la acción de la Unión en la escena internacional se basará en principios entre los que se encuentran «el Estado de Derecho, y la universalidad e indivisibilidad de los derechos humanos y de las libertades fundamentales, que, sin duda, incluyen el derecho de acceso a la justicia y a la tutela judicial efectiva» ${ }^{71}$.

En este contexto, el art. 47 de la Carta de los Derechos Fundamentales de la UE cobra una relevancia que no había tenido en los asuntos anteriores y que le lleva a decir que «Si bien el artículo 47 de la Carta no puede crearle al Tribunal de Justicia una competencia cuando los Tratados excluyen esa posibilidad, el principio de tutela judicial efectiva conlleva que la exclusión de la competencia del Tribunal de Justicia en materia de PESC debe interpretarse restrictivamente» ${ }^{72}$, enriqueciendo así la defensa de este argumento ya apuntado por el TJ con anterioridad.

\subsection{La vigencia de la doctrina Foto-Frost en la PESC: atajando desviaciones peligrosas}

Por último, el TJ dirime de forma inequívoca un problema importante relacionado con el alcance del papel de los tribunales nacionales, a los que la ausencia de competencias del TJUE sobre buena parte de los actos PESC deriva el control jurisdiccional. La incógnita se abrió cuando en su opinión con ocasión del Dictamen 2/13, al hilo de su posición contraria al reenvío prejudicial en la PESC, la abogada general defendió que la tutela judicial podía venir asegurada por los órganos jurisdiccionales nacionales, que a su juicio se presentan en todo caso al particular como la vía obvia para someter al control jurisdiccional los actos, medidas u omisiones que se produzcan

71 Punto 66 de las conclusiones (op. cit., nota 43).

72 Apdo. 74 de la sentencia (op. cit., nota 4). Sobre los argumentos ahora comentados, véanse también los apdos. 72-73 de la sentencia (ibid.). Hay que recordar que en el tenor literal de la cuestión prejudicial planteada, el órgano jurisdiccional nacional citaba expresamente el art. 47 de la Carta. 
en el contexto de la PESC y de algún modo le afecten ${ }^{73}$. En este orden de ideas, su argumentación se complicó porque planteó el dilema de si la jurisprudencia Foto-Frost es trasladable a este ámbito, respondiendo de forma negativa y manteniendo que los propios tribunales nacionales «deben analizar, cuando corresponde, la compatibilidad con las normas superiores del Derecho de la Unión de los actos adoptados en el contexto de la PESC por las instituciones, órganos y organismos de la Unión y, en caso de que sean incompatibles, dejarlos inaplicados en el litigio de que se trate», ya que a su juicio «la jurisprudencia reiterada del Tribunal de Justicia que tiene su origen en la sentencia Foto-Frost no es trasladable a la PESC» ${ }^{74}$. Kokott justificó tan sorprendente opinión en que «tal es la consecuencia lógica de la decisión de los autores de los Tratados de seguir estructurando la PESC en lo esencial como intergubernamental y de limitar a los casos excepcionales que se enumeran de forma exhaustiva en el artículo 275 TFUE, párrafo segundo, el componente supranacional que es inherente a todas las competencias de nuestro Tribunal de Justicia» ${ }^{75}$.

En cambio, en sus conclusiones en el asunto H/Consejo y Comisión, el abogado general Wahl sostuvo que el principio enunciado en Foto-Frost también es aplicable en la PESC, de manera que cuando un órgano jurisdiccional nacional ante el que se impugna un acto PESC de la Unión llegara a la conclusión de que es ilegal por vulnerar normas de la Unión de rango superior, podría, a lo sumo, suspender la aplicación del acto en relación con el demandante y, en su caso, concederle una indemnización, conforme a la jurisprudencia Zuckerfabrik ${ }^{76}$.

Con estos antecedentes, al plantear su cuestión en el asunto Rosneft el tribunal remitente apuntó expresamente, citando Foto-Frost, que estimaba que él no era competente para realizar un control de validez de actos de derecho de la Unión $^{77}$. En la sentencia, el Tribunal encuentra en este tema otro argumento

73 Punto 98 de la opinión (op. cit., nota 24). Para el conjunto de este razonamiento, véanse también los puntos 96, 97 y 99 (ibid.).

74 Punto 100 de la opinión (ibid.).

75 Punto 101 de la opinión (ibid.).

76 Puntos 102-103 de las conclusiones (op. cit., nota 23).

77 Véase el apdo. 34 de la sentencia (op. cit., nota 5). Este tema del papel de los tribunales nacionales fue objeto de diversas intervenciones durante la vista oral (véase Stian Øby JOHNSEN, »«A report from the oral hearing in Case C-72/15 (Rosneft)», Øby-kanalen, disponible en https://obykanalen.wordpress.com/2016/02/25/a-report-from-the-oral-hearing-in-case-c-7215-rosneft/, consultado por última vez el 25.9.2017); del mismo autor y con el mismo contenido: «EU sanctions against nonEU countries: the CJEU will soon address some key legal issues", EU Law Analysis, 
a favor de declararse competente para resolver cuestiones prejudiciales y de no confiar exclusivamente a los tribunales nacionales la garantía de la tutela judicial efectiva. Así, entiende que la razón de ser de la doctrina Foto-Frost, consistente en asegurar la coherencia del sistema de protección judicial, lo que exige que la facultad de declarar la nulidad de los actos de las instituciones de la Unión esté reservada al Tribunal de Justicia en el marco del art. 267 TFUE, se aplica también «a las decisiones adoptadas en materia de PESC y respecto de las que los Tratados confieren al Tribunal de Justicia competencia para el control de legalidad $»^{78}$.

Es significativo que en los asuntos Gestoras pro Amnistía y otros/Consejo y Segi y otros/Consejo también el abogado general defendió que la regla Foto-Frost no era aplicable al ámbito del título VI del TUE y por tanto que los jueces nacionales dispusieran de competencia para declarar la invalidez de decisiones-marco o de decisiones adoptadas en el marco del art. $34 \mathrm{TUE}^{79}$. En aquella ocasión, y a diferencia de lo que ha hecho en Rosneft, el TJ no se pronunció sobre este aspecto. Ahora lo hace y con ello pone fin a una ambigüedad que podía acabar causando problemas ${ }^{80}$.

disponible en http://eulawanalysis.blogspot.com.es/2016/02/eu-sanctions-against-noneu-countries.html (consultado por última vez el 25.9.2017).

78 Apdo. 78 de la sentencia (ibid.). Para el TJ, «Tal conclusión se ve corroborada por el objetivo esencial del artículo 267 TFUE, que es garantizar la aplicación uniforme del Derecho de la Unión por parte de los órganos jurisdiccionales nacionales y que se impone con la misma fuerza tanto en el control de legalidad de las decisiones mediante que prevén la adopción de medidas restrictivas frente a personas físicas o jurídicas como en otros actos de la Unión. En efecto, por lo que se refiere a dichas decisiones, las divergencias entre los órganos jurisdiccionales nacionales de los Estados miembros sobre la validez de los actos de la Unión pueden llegar a comprometer la unidad misma del ordenamiento jurídico de la Unión y vulnerar la exigencia fundamental de seguridad jurídica [...]» (apdo. 80 de la sentencia, ibid.). Aunque sin tanto énfasis, el abogado general también había traído a colación la sentencia Foto-Frost (véase el punto 63 de las conclusiones, op. cit., nota 43).

79 Véanse las conclusiones del abogado general Mengozzi en los asuntos Gestoras pro Amnistía y otros/Consejo y Segi y otros/Consejo, C-354/04 P y C-355/04 P, EU:C:2006:667, puntos 118-132.

80 Sirva como muestra el dato de que en el auto impugnado en el asunto H/Consejo y Comisión el TG consideró que el juez italiano podría anular las decisiones del jefe de la misión de policía de la UE en Bosnia-Herzegovina si sobrepasaban los poderes que — según su peculiar interpretación- le habían delegado las autoridades nacionales (Auto del Tribunal General, T-271/10, H/Consejo, EU:T:2014:702, apdo. 53). 


\section{EL RESULTADO: LA PROCLAMACIÓN DE LA COMPETENCIA PREJUDICIAL DE VALIDEZ DEL TJ SOBRE LOS ACTOS PESC SIN INMUNIDAD JURISDICCIONAL}

La argumentación hasta aquí analizada permite al Tribunal ofrecer la tan esperada respuesta, que expresa de la manera siguiente:

Los artículos 19 TUE, 24 TUE y 40 TUE, el artículo 275 TFUE y el artículo 47 de la Carta deben interpretarse en el sentido de que el Tribunal de Justicia es competente para pronunciarse con carácter prejudicial con arreglo al artículo 267 TFUE sobre la validez de actos que, como la Decisión 2014/512, hayan sido adoptados sobre la base de las disposiciones relativas a la PESC, siempre que las peticiones de decisión prejudicial correspondientes versen bien sobre el control de si dichas decisiones respetan el artículo 40 TUE bien sobre el control de legalidad de medidas restrictivas adoptadas frente a personas físicas o jurídicas ${ }^{81}$.

Ello le permite proceder a controlar, de un lado, el respeto del art. 40 TUE por parte de la Decisión 2014/512; de otro, la validez de las medidas restrictivas establecidas frente a personas físicas o jurídicas en la Decisión 2014/512 y el Reglamento n. ${ }^{\circ}$ 833/2014. No es objeto de este trabajo analizar los aspectos sustantivos que se plantean al respecto, pero sí tiene interés consignar que la delimitación material fijada por el TJ respecto del alcance de la segunda dimensión de su competencia prejudicial, esto es, las medidas restrictivas adoptadas frente a personas físicas o jurídicas, le conduce a dilucidar qué disposiciones de la Decisión 2014/512 contienen este tipo de medidas y cuáles, por el contrario, son objetivas y de alcance general. Para ello, enlaza con su jurisprudencia anterior relativa a la naturaleza de estas medidas, según la cual las medidas restrictivas se asemejan tanto a los actos de alcance general, en la medida en que prohíben a una categoría general y abstracta de destinatarios poner recursos económicos a disposición de entidades cuyos nombres figuran en sus anexos, como a decisiones individuales adoptadas frente a tales entidades, de forma que por lo que se refiere a los actos adoptados sobre la base de las disposiciones relativas a la PESC, es la naturaleza individual de esos actos la que da, con arreglo a lo dispuesto en el art. 275 TFUE, párrafo segundo, acceso a los tribunales de la Unión ${ }^{82}$.

81 Apdo. 81 de la sentencia (op. cit., nota 5).

82 Así lo afirmó en la Sentencia del Tribunal de Justicia Kadi y Al Barakaat International Foundation/Consejo y Comisión, C402/05 P y C415/05 P, EU:C:2008:461 y en la Sentencia del Tribunal de Justicia Gbagbo y otros/Consejo, C478/11 P a C482/11 P, EU:C:2013:258 (véanse los apdos. 102-103 de la sentencia, ibid.). 
Todo ello le lleva a concluir que el Tribunal de Justicia es competente para pronunciarse sobre la validez del artículo 1, apdos. 2, letras b) a d), y 3, del art. 7 y del anexo III de la Decisión 2014/512; en cambio, no es competente para controlar la validez de los art. 4 y 4 bis de esta decisión. En consecuencia, advierte de que «habrán de tenerse en cuenta estos límites de la competencia del Tribunal de Justicia a la hora de examinar la validez de las disposiciones a que se refiere el órgano jurisdiccional remitente» ${ }^{83}$. Estas precisiones son relevantes porque seguramente marcan la línea de actuación que el TJ tendrá que seguir en futuros casos en los que se le planteen cuestiones prejudiciales de este tipo.

\section{4. ¿̇Y LA COMPETENCIA PREJUDICIAL DE INTERPRETACIÓN?}

La primera cuestión prejudicial planteada por el Tribunal Superior de Justicia (Inglaterra y País de Gales), de cuya respuesta hemos venido ocupándonos hasta aquí, era de validez, y es en relación con esa dimensión del reenvío prejudicial sobre lo que se pronuncia el Tribunal, afirmando su competencia con la precisión que hemos visto. Sin embargo, la tercera cuestión prejudicial, letra c), pedía también una interpretación no solo de algunos artículos del Reglamento no 833/2014, sino también de determinadas expresiones contempladas en el art. 4 de la Decisión 2014/512 ${ }^{84}$. Curiosamente, al abordar esa cuestión, el TJ solo menciona el reglamento, silenciando por completo la decisión y sin proporcionar ninguna explicación acerca de esta omisión ${ }^{85}$. De esta forma, el Tribunal evita pronunciarse sobre si en la PESC, además de tener competencia prejudicial de validez, la tiene también de interpretación, siempre claro está dentro de los límites ya apuntados. Seguramente, el hecho de que esta parte de la cuestión prejudicial no cumpliera los requisitos de admisibilidad ni siquiera en lo relativo al Reglamento, pues en opinión del TJ el tribunal remitente no explicó por qué unas definiciones precisas de esos con-

83 Apdo. 107 de la sentencia (ibid.).

84 Se trataba de las expresiones «esquisto" y "aguas con una profundidad superior a 150 metros». Como resume la sentencia en su apdo. 36, «Para el supuesto de que el Tribunal de Justicia declare válidos los actos controvertidos, el tribunal remitente expresa dudas sobre la interpretación de los mismos. Estimando que los términos de las medidas restrictivas controvertidas en el litigio principal deben interpretarse de manera uniforme en toda la Unión, el tribunal remitente explica que durante el procedimiento principal ha constatado discrepancias en la práctica de las autoridades de otros Estados miembros por lo que atañe a la interpretación que se haya de dar a determinadas disposiciones de los actos controvertidos».

85 Véanse los apdos. 191-196 de la sentencia (op. cit., nota 5). 
ceptos son necesarias para resolver el litigio del que conoce, facilitó este ejercicio de escapismo judicial que impide obtener la respuesta completa al tema de la cuestión prejudicial en la PESC. Con todo, hay dos elementos que pueden resultar útiles en la búsqueda de la solución, por más que no sean definitivos.

El primero lo proporciona el abogado general, quien sí se planteó la pregunta: “¿Qué ocurre con el poder de interpretación?»" Tras reconocer que como la cláusula introducida por el art. 24 TUE, apdo. 1, párrafo segundo, última frase, y por el art. 275, párrafo segundo TFUE, limita la competencia del Tribunal de Justicia a un control de legalidad, el poder de interpretación parece estar excluido, considera que la sentencia Busseni ${ }^{87}$, en la que - pese a que el art. 41 TCECA solo contemplaba explícitamente la competencia del TJ en relación con la cuestión prejudicial de validez- el Tribunal interpretó que sería contrario a la finalidad y a la coherencia de los tratados que mientras que en las otras dos comunidades la fijación del sentido y alcance de las normas establecidas en los tratados le correspondiera a él en última instancia, en el caso de la CECA no se garantizara la interpretación uniforme. A este argumento, que al abogado general le parece que proviene de un marco jurídico comparable, añade el derivado del aforismo «quien puede lo más, puede lo menos».

El segundo elemento se encuentra en un asunto resuelto por el TJ tan solo unos días antes de la sentencia Rosneft. Se trata de la sentencia de 14 de marzo de 2017, también de Gran Sala, en el asunto $A$ y tros $^{88}$, que obedece a una petición de decisión prejudicial, en parte de interpretación y en parte de validez, formulada por el Raad van State (Consejo de Estado, Países Bajos). Entre los textos implicados en interpretación estaba la Posición Común 2001/931/PESC del Consejo, de 27 de diciembre de 2001, sobre la aplicación de medidas específicas de lucha contra el terrorismo; en concreto, se trataba del concepto de «actos terroristas». En sus conclusiones, la abogada general se planteó si el TJ era competente para interpretar la Posición Común, que es un acto de la PESC, recordando al respecto la norma general de ausencia de competencia y las excepciones a la misma. En este sentido, afirmó que «Ello no abarca, prima facie, la interpretación o el control de la legalidad de tales actos en el marco del procedimiento de remisión prejudicial ${ }^{89}$, pero añadió que compartía la postura del abogado general Wathelet en el asunto Rosneft

86 Título del apdo. V. A. iii) de las conclusiones del abogado general Wathelet en el asunto Rosneft (op. cit., nota 43).

87 Sentencia del Tribunal de Justicia CECA/Busseni, C-221/88, EU:C:1990:84.

88 Sentencia del Tribunal de Justicia A y otros, C-158/14, EU:C:2017:202.

89 Conclusiones de la abogado general Sharpston en el asunto $A$ y otros, punto 90 (op. cit., nota 42). 
en el sentido de que el control de legalidad no solo comprende los recursos de anulación, sino también la cuestión prejudicial ${ }^{90}$.

Sorprendentemente, en su sentencia el Tribunal no entra a analizar este importante aspecto y procede sin más a interpretar la Posición Común. No parece aventurado pensar que este caso permite presagiar una actitud positiva del TJ hacia la asunción de competencia para interpretar prejudicialmente actos PESC.

\section{REFLEXIÓN FINAL: EL TRIUNFO DE LA COHERENCIA DEL SISTEMA SOBRE LA LITERALIDAD DE LOS PRECEPTOS}

Las características del conjunto normativo de la PESC, acertadamente calificado como lex imperfecta por el abogado general Wahl ${ }^{91}$, ponen a prueba aspectos fundamentales del derecho de la UE vinculados al principio de Estado de derecho, al respeto de los derechos fundamentales y al papel del Tribunal de Justicia como garante de la aplicación e interpretación uniforme de este ordenamiento. A la espera de que los dueños de los tratados remedien las deficiencias estructurales actualmente existentes, es razonable pensar que corresponde al TJUE utilizar los medios a su alcance ${ }^{92}$. Así lo ha hecho en el asunto Rosneft.

90 En su opinión, «El mecanismo de remisión prejudicial en asuntos que incluyen el control de la legalidad representa un papel crucial a este respecto para personas que... podrían resultar perjudicadas por las medidas de la PESC no dirigidas a ellas individualmente $y$, por consiguiente, en principio sin legitimación para interponer un recurso de anulación contra dichas medidas ante los órganos jurisdiccionales de la Unión con arreglo al artículo 275 TFUE, párrafo segundo. Tal y como sostiene el Abogado General Wathelet, además, la competencia del Tribunal de Justicia para controlar la legalidad de medidas restrictivas frente a personas físicas o jurídicas adoptadas en virtud del capítulo 2 del título $\mathrm{V}$ del TUE, en el contexto de un procedimiento de remisión prejudicial, conlleva necesariamente el poder de interpretación de tales actos» (punto 90 de las conclusiones, ibid.). Conviene advertir que en la última frase del punto 91 de la versión en español de estas conclusiones hay una errata importante, pues dice: «En consecuencia, el Tribunal de Justicia no es competente para responder [...]» (cursiva añadida), lo que es contradictorio con las afirmaciones del punto anterior. La consulta de otras versiones lingüísticas confirma la existencia de la errata.

91 En sus conclusiones en el asunto H/Consejo y Comisión, punto 38 (op. cit., nota 23).

92 Como apunta Thomas VERELLEN, «it is incumbent on the CJEU to interpret the scope of its jurisdiction over CFSP-related disputes broadly, if only because exceptions are to be interpreted narrowly, and should not prevent the CJEU from providing relief where Member State courts are not in position to do so effectively» (op. cit., nota 21, p. 1053). 
En vez de caer en la tentación de abordar la cuestión en términos estrictos de competencias de atribución, haciendo interpretaciones literales del tenor de los arts. 24 TUE y 275 TFUE, el Tribunal ha sabido encontrar en los valores y principios sobre los que reposa la UE, y en su propia jurisprudencia acerca del sistema de protección jurisdiccional, las claves para afirmar su competencia prejudicial en un ámbito en el que, dado que los Estados han querido que su intervención sea limitada y por tanto se deja más espacio a los tribunales nacionales, la cooperación entre ambos niveles judiciales es especialmente importante. En este sentido, el recurso a una perspectiva sistémica confirma que, como se ha apuntado, «the EU Treaty provisions relating to the CFSP -including the part on the limits to the Court's jurisdiction - cannot be interpreted in isolation from the general structure and logic of the Treaties» ${ }^{93}$. En particular, se ratifica la aplicación transversal de los principios constitucionales de la UE, que se proyectan sobre el principio de atribución de competencias con la consecuencia de impedir una interpretación restrictiva del mismo ${ }^{94}$.

Mediante esta sentencia, el TJ ha abierto la puerta a que los órganos jurisdiccionales nacionales utilicen, en relación con los actos de la PESC, lo que él mismo ha denominado "la piedra angular del sistema jurisdiccional»" si bien circunscribiéndola inevitablemente a los actos de naturaleza individual de ese ámbito que conforme a los tratados no están cubiertos por la inmunidad jurisdiccional. La pregunta formulada por el Tribunal Superior de Justicia (Inglaterra y País de Gales), que le ha dado al TJUE la oportunidad de dar este salto cualitativo, demuestra que aquellos están dispuestos a hacerlo. Desde la perspectiva de la tutela judicial efectiva, es una buena noticia. También lo es el que, en estos tiempos de Brexit, el cooperador necesario haya sido un tribunal británico.

93 Peter VAN ELSUWEGE, «Judicial Review of the EU’s Common Foreign and Security Policy: Lessons from the Rosneft case», VerfBlog, disponible en http://verfassungsblog. de/judicial-review-of-the-eus-common-foreign-and-security-policy-lessons-from-therosneft-case/, (consultado por última vez el 25.9.2017).

94 Se corrobora así el pronóstico avanzado por Christophe HILLION sobre la aplicación de estos principios en la PESC y la competencia del Tribunal para garantizarla (op. cit., nota 2, pp. 68-69). Sobre la aplicación del principio de atribución al TJUE, puede verse Koen LENAERTS, «Les fondements constitutionnels de l'Union Européenne dans leur rapport avec le droit international», en Antonio TIZZANO; Allan ROSAS; Rosario SILVA DE LAPUERTA; Koen LENAERTS; Juliane KOKOTT (dirs.), La Cour de justice de l'Union Européenne sous la présidence de Vassilios Skouris (20032015). Liber Amicorum Vassilios Skouris, Bruylant, Brussels, 2015, p. 372.

95 Dictamen del Tribunal de Justicia 2/13, apdo. 176 (op. cit., nota 3). 